\title{
Cognição Social e Teoria do Apego: Possíveis Articulações
}

\author{
Vera Regina Röhnelt Ramires ${ }^{12}$ \\ Universidade do Vale do Rio dos Sinos, Rio Grande do Sul
}

\begin{abstract}
Resumo
Esse artigo discute a possibilidade de articulação de conceitos da teoria do apego e da teoria da cognição social. Conceitos-chave de ambas as teorias são apresentados, procurando-se analisar algumas das suas interfaces. Ao assumirmos uma perspectiva epistemológica complexa, não linear, domínios teóricos tradicionalmente considerados antagônicos, como a teorização sobre o pensamento e aquelas sobre sentimentos têm se entrelaçado para a abordagem teórica e clínica de problemáticas recentes. Concluímos que essa articulação poderia criar um campo conceitual novo, o qual demanda pesquisas e uma teorização aprofundada, possuindo implicações para a compreensão do desenvolvimento infantil, para o âmbito da clínica psicológica e para o campo da construção do conhecimento.

Palavras-chave: Cognição social; apego; cognição e afeto; desenvolvimento infantil.
\end{abstract}

Social Cognition and Attachment Theory: Some Approximations

\begin{abstract}
This paper discusses the possible approximation of concepts of attachment theory and social cognition. Key-concepts of both theories are presented, aiming to analyse their interfaces. That approximation could create a new conceptual field, which demands research and theoretical construction, and has implications to the understanding of child development, for both clinical psychology and the construction of knowledge.

Keywords: Social cognition; attachment; affect and cognition; child development.
\end{abstract}

O objetivo deste artigo é discutir a correspondência e a possibilidade de articulação de conceitos da teoria do apego (Bowlby, 1969/1990, 1973/1998a, 1973/1998b, 1979/1997, 1988/1989) e da teoria da cognição social. Tal articulação sustentou a análise das concepções de crianças e adolescentes acerca dos vínculos amorosos, em pesquisa recentemente concluída (Ramires, 2002). No estudo referido, buscou-se compreender as concepções de participantes entre 5 e 15 anos de idade, de classe média urbana, acerca do amor, dos vínculos amorosos e suas vicissitudes, no contexto do rompimento dos vínculos conjugais (das separações e divórcios).

E uma vez que o divórcio foi compreendido como um processo complexo em que a vivência das crianças e dos adolescentes depende de uma série de condições, a análise das entrevistas foi sustentada pela articulação de conceitos da teoria da cognição social e da teoria do apego. À primeira vista, tais conceitos poderiam ser considerados como separados e independentes. Entretanto, numa epistemologia não linear, conforme salienta Forgas (2001), domínios teóricos tradicionalmente considerados

\footnotetext{
${ }^{1}$ A autora agradece a Universidade do Vale do Rio dos Sinos o apoio para a realização da pesquisa que deu origem a este artigo.

${ }^{2}$ Endereço para correspondência: Av. Carlos Gomes 911, 201, 90480004 , Porto Alegre, RS. E-mail: veraramires@terra.com.br
}

antagônicos, como a teorização sobre o pensamento e aquelas sobre o sentimento, têm se entrelaçado para a abordagem teórica e clínica de problemáticas recentes. De planos de análise dissociados, a cognição e os sentimentos podem se associar e possibilitar uma interface que pode ser promissora para tal abordagem.

Desta forma, a compreensão e a interpretação da fala dos entrevistados esteve baseada na teoria da cognição social e na teoria do apego. Ao se penetrar nas proposições de uma e de outra, pode-se constatar uma correspondência estreita entre muitos dos seus conceitos. Além disso, seria difícil compreender as concepções das crianças e adolescentes sobre o amor e os vínculos amorosos, analisando essas concepções a partir de uma dimensão cognitiva ou afetiva, exclusivamente.

Lamb e Sherrod (1981) já salientaram que a cognição social situa-se na intersecção de várias áreas - perceptiva, cognitiva, social, emocional, e desenvolvimento da personalidade. Conseqüentemente, mais do que qualquer outro tópico, esta área demanda que os teóricos e pesquisadores reconheçam as influências mútuas e interrelações entre desenvolvimentos em áreas muito diversas. Além disso, como a cognição social procura integrar diversas áreas da psicologia do desenvolvimento, seu estudo facilita abordagens mais abrangentes, as quais facilmente ficam comprometidas quando o foco é muito estreito. Eles se referem particularmente às bases biológicas do 
desenvolvimento, à variabilidade cultural e ao contexto sóciopolítico ou ecológico no qual o desenvolvimento tem lugar.

Mais recentemente, Forgas (2001) testemunha a necessidade da abordagem do afeto e da cognição como dimensões entrelaçadas e inseparáveis da vida social humana. Considera que pesquisas neste tópico realizadas nos últimos anos vêm promovendo conceitualizações dinâmicas e genuinamente interativas dos links entre afeto e cognição social.

Por outro lado, os estudiosos do campo da teoria do apego, a começar pelo próprio Bowlby, salientam os seus estreitos laços com a psicologia cognitiva, na medida em que essa teoria possibilita articulações entre os processos interpessoais e o desenvolvimento cognitivo e o social (Bowlby, 1979/1997; Cook, 2000; Rothbard \& Shaver, 1994).

Sendo assim, para compreender as concepções dos entrevistados acerca dos vínculos amorosos, é que foi necessário articular conceitos que se originam na teoria do apego, com a sua contribuição sobre como se constroem e se vivenciam os vínculos amorosos, e na teoria da cognição social que descreve como se pensa sobre esses vínculos, como se lhes dá significado. Levando também em conta alguns conceitos sobre o divórcio e sobre as crenças sociais acerca do amor, os quais se inseriram nesse estudo enquanto elementos importantes do contexto, a contribuir na construção de tais significados.

\section{A Cognição Social e os Vínculos Afetivos}

A pesquisa no campo da cognição social começou a ser desenvolvida no início dos anos 1970, sendo definida por Lamb e Sherrod (1981) como a forma através da qual os indivíduos percebem e compreendem outras pessoas. Fiske e Taylor (1991) incluem nessa conceitualização, além da cognição sobre as outras pessoas, a cognição sobre elas mesmas, considerando não apenas a forma como as pessoas pensam sobre as outras, mas também a forma como elas pensam que pensam sobre as outras.

Flavell, P. H. Miller e S. A. Miller (1999) explicitam no conceito a cognição sobre as pessoas e suas ações e Bee (1996) acrescenta que, além do pensar sobre as pessoas e sobre o que elas fazem, a cognição social inclui também o pensar sobre o que as pessoas deveriam fazer e como elas se sentem.

Uma definição mais completa, a nosso ver, é oferecida por Fu, Goodwin, Sporakowki e Hinkle (1987), na medida em que esses autores ampliam o conceito para além da compreensão das relações sociais, objetos e eventos sociais. Eles consideram que a cognição social abrange mais do que a percepção e as inferências sobre outras pessoas, envolvendo a compreensão das relações entre os próprios sentimentos, pensamentos e ações, tanto quanto as relações entre esses fatores pessoais e os fatores correspondentes nas outras pessoas. Isso implica que, da perspectiva da cognição social, nossa compreensão da interação social depende da nossa organização dos conceitos sociais e da habilidade de integrar e coordenar perspectivas.

Lamb e Sherrod (1981) indicam que o processo através do qual as crianças desenvolvem a sua compreensão do ambiente social e do seu papel nele é complexo e multifacetado. As pesquisas relevantes nesse campo focalizaram, por exemplo, o desenvolvimento da capacidade de identificar, lembrar e reconhecer objetos sociais, no caso as pessoas, como distintas dos objetos inanimados do ambiente; o desenvolvimento da capacidade de fazer inferências sobre as probabilidades comportamentais, motivações e emoções das outras pessoas; a habilidade da criança de atribuir significado as suas experiências sociais; e focalizaram, ainda, o conceito de self que a criança desenvolve e quais são os mecanismos subjacentes a esse desenvolvimento.

A cognição social reconhece a criança ativa e interativa, atribuindo a ela um papel construtivo no seu desenvolvimento. Mais do que uma receptora de inputs sociais, essa criança é um ator pensante no mundo das pessoas. Há muito tempo tem sido reconhecido que as primeiras experiências relacionais desempenham um papel importante no curso do desenvolvimento, mas pouco se sabe sobre os processos através dos quais isso ocorre. Avanços nesse conhecimento dependem de que se possa compreender não apenas o que é feito à criança, mas como ela percebe o que lhe acontece. É daí que surge a demanda da pesquisa no campo da cognição social.

O desenvolvimento sócio-cognitivo, portanto, começa com os primórdios do processo de separação-individuação e conexão emocional com o outro nos bebês. Esse desenvolvimento inclui a compreensão crescente das emoções e dos perceptos, e também o conhecimento das crianças e dos adolescentes acerca dos atributos pessoais dos outros e do self. Inclui ainda o conhecimento das causas do comportamento e uma compreensão das relações sociais que implicam no reconhecimento de relações recíprocas como a amizade, os relacionamentos amorosos e os julgamentos morais.

Nesse sentido, seria importante a investigação do desenvolvimento do auto-conceito e do desenvolvimento emocional. Que conceito de self uma criança tem e que mecanismos são subjacentes ao desenvolvimento desse conceito? Que emoções uma criança experimenta e quando essas emoções passam a colorir sua percepção das pessoas e dos eventos? E ainda, como as crianças aprendem a reconhecer e atribuir significado às expressões emocionais dos outros? 
A teoria da cognição social busca integrar os vários aspectos do desenvolvimento sócio-cognitivo, possibilitando a análise da compreensão que crianças e adolescentes têm dos relacionamentos sociais, inclusive dos relacionamentos que implicam em conexões sócio-emocionais.

\section{A Transformação do Bebê em um Pensador Social}

Flavell e colaboradores (1999) caracterizam parte do desenvolvimento sócio-cognitivo do bebê como um processo de separação e diferenciação. Esse processo implica numa diferenciação gradativa entre self e não-self, entre objetos humanos e não humanos e entre um objeto humano e outro. Self é o conceito que indica, para os autores, o "eu" da mente e uma tarefa central para a criança é que ela adquira uma noção de si mesma como entidade distinta e separada, diferenciada das outras e ao mesmo tempo conectada emocional e socialmente a elas.

Esse processo de articulação e definição do self começa cedo na vida do bebê, da mesma forma que os bebês aprendem muito cedo que os seres humanos são objetos especiais com os quais eles poderão interagir de maneiras muito especiais. Os objetos humanos também se tornam gradualmente distintos dos não humanos para os bebês. Eles aprendem que as pessoas e não os objetos respondem aos seus sinais; aprendem que o comportamento das outras pessoas pode ser previsível e contingente ao seu próprio comportamento; aprendem que a contingência vai na direção oposta também - as outras pessoas agem, e o bebê reage apropriadamente, o que lhe possibilita expandir sua consciência das contingências recíprocas.

As interações recíprocas, portanto, é que possibilitam o processo de diferenciação do self. Além disso, as primeiras tentativas de um bebê de se comunicar, as quais também são tentativas de se conectar com outras pessoas, ampliam sua capacidade de responder aos gestos e expressões faciais de emoção dos outros. Os bebês aprendem a usar esse repertório de expressões como um guia para ações prudentes, comportamento chamado de referenciamento social (Bee, 1996; Flavell \& cols., 1999).

Ao final do primeiro ano de vida, os bebês estarão minimamente conscientes da existência das experiências internas - desejos, emoções, intenções, e de que estes estados internos podem ser compartilhados com outras pessoas. Entretanto, o ponto máximo das conexões com os outros apontado por Flavell e colaboradores (1999) é o que eles chamam de apego social e que se baseia na descrição de Bowlby (1969/1990). O apego social resulta do desenvolvimento de laços carregados de afeto com algumas pessoas, tais como a mãe e o pai e ele é um processo de interação social de duas vias, na medida em que envolve sempre os sentimentos e comportamentos dos pais e do bebê. Por volta dos 9 meses, os bebês começam a mostrar sinais claros de formação de apegos sociais específicos.

Ao utilizar o conceito de apego de Bowlby, acredita-se que esses autores conseguem estabelecer uma articulação importante entre o desenvolvimento cognitivo e o afetivo e descrever desta forma duas dimensões indissociáveis de um mesmo processo que é o desenvolvimento infantil.

Revisando-se a literatura disponível sobre a teoria da cognição social, pode-se constatar que grande parte dela está entrelaçada com as contribuições da teoria do apego, a qual constitui uma citação quase que obrigatória (Bee, 1996; Baldwin, Keelan, Fehr, Enns \& Koh-Rangarajoo, 1996; Flavell \& cols., 1999; Frye, 1981; Lamb, 1981; Olson, 1981; Oster, 1981).

Por outro lado, Cook (2000) afirma que a teoria do apego de Bowlby não descreve apenas como os modelos internalizados dos relacionamentos afetam as relações interpessoais em geral. Mas entende que ela é "primariamente uma teoria sobre como os processos interpessoais afetam o desenvolvimento cognitivo e o social" (p. 285). Da mesma forma, Rothbard e Shaver (1994) destacam que "O amplo apelo da teoria do apego está baseado na sua habilidade para combinar aspectos das perspectivas etológica, psicanalítica e cognitiva-social num conjunto de proposições integrativo, rico e empiricamente testável, concernentes ao comportamento social e à personalidade" (p. 31).

O próprio Bowlby (1979/1997) acentua que sua teoria, embora incorporando muito do pensamento psicanalítico, distancia-se da psicanálise tradicional na medida em que adota princípios de disciplinas como a etologia por exemplo. E que ao fazê-lo, "está habilitada a dispensar conceitos tais como os de energia psíquica e impulso, e a estabelecer estreitos laços com a psicologia cognitiva" (p. 168).

A teoria do apego confere uma nova dimensão para a compreensão da natureza e origem dos vínculos afetivos. Como Bowlby (1979/1997) assinala, até meados da década de 1950 predominava uma concepção de que a formação e manutenção dos vínculos sustentavam-se na necessidade de satisfazer certos impulsos, como a alimentação na infância e o sexo na vida adulta. Em contrapartida, este autor irá alicerçar sua teoria no pressuposto, amparado pelo relato de farta pesquisa empírica, de que existe nos bebês uma propensão inata para o contato físico com um ser humano, o que significa a existência da "necessidade" de um objeto independente do alimento, tão primária quanto a "necessidade" de alimento e conforto (Bowlby, 1969/1990).

Esse vínculo da criança com sua mãe, ou seu principal cuidador, resulta da atividade de um certo número de sistemas comportamentais que tem na proximidade com a 
mãe o seu resultado previsível. Assim, por exemplo, nos bebês, a partida da mãe ou algum estímulo assustador ativam certos sistemas comportamentais, finalizados pelo som, pela visão ou pelo contato da mãe.

Bowlby (1969/1990) acredita que:

...o comportamento de apego é considerado uma classe de comportamento social de importância equivalente à do comportamento de acasalamento e do parental. Sustenta-se que tem uma função biológica que lhe é específica e que até agora tem sido pouco considerada. (p. 194)

No entanto, essa visão não implica em lançar mão de conceitos tais como necessidade ou impulso, já que para o autor os sistemas comportamentais se desenvolvem no bebê como resultado de sua interação com o seu meio ambiente e, em especial, de sua interação com a principal figura nesse meio ambiente, ou seja, a mãe. A alimentação e o alimento desempenham um papel secundário no desenvolvimento desses sistemas.

Portanto, tais sistemas comportamentais transcendem o que é chamado de comportamento "instintivo", seja qual for a acepção do termo. Bowlby (1969/1990) levanta esse argumento ao destacar o papel da linguagem, característica singular do equipamento comportamental humano. A linguagem traz como benefício a possibilidade para o ser humano, ao construir seus modelos representacionais, de apoiar-se nos modelos construídos pelos outros. Os sistemas comportamentais são organizados hierarquicamente por meio da linguagem e contam com a possibilidade de se apoiarem em modelos representacionais refinados do organismo e do ambiente. Por esse motivo, o autor conclui que boa parte do comportamento humano não pode ser chamada de "instintiva", seja o que for que isto queira significar.

O comportamento de apego, portanto, compreende qualquer forma de comportamento que implique em alcançar ou manter uma proximidade com outro indivíduo, diferenciado e preferido, e geralmente considerado como mais forte ou mais sábio. Tal comportamento é especialmente evidente nos primeiros anos, mas Bowlby (1979/1997) afirma que ele caracteriza os seres humanos durante toda a sua vida. O choro e o chamamento fazem parte dos comportamentos de apego, suscitando cuidados, atenção, acompanhamento e apego, ou vigorosos protestos se a criança for deixada sozinha ou na companhia de estranhos. $\mathrm{Na}$ medida em que a criança cresce, diminuem gradativamente a intensidade e a freqüência desses comportamentos, os quais, no entanto, persistem como parte integrante do equipamento comportamental humano, e suscetível de ser ativado quando a pessoa estiver assustada, doente ou consternada, por exemplo. A idade atual, o sexo e as circunstâncias, por um lado, e as experiências com as figuras de ligação nos primeiros anos de vida, por outro, determinam os padrões de comportamento de ligação manifestados por uma pessoa.

A teoria da cognição social elucida de que forma o desenvolvimento cognitivo auxilia e possibilita a formação do apego. Flavell e colaboradores (1999) descrevem cinco pré-requisitos cognitivos para a formação do apego. $\mathrm{O}$ primeiro deles depende da capacidade crescente dos bebês de fazer discriminações visuais finas, o que thes possibilita, entre outras coisas, discriminar rostos e reconhecer ou identificar rostos especiais, recorrentes, familiares. O segundo pré-requisito seria o potencial do bebê para processar os sons da fala humana, preferi-los em relação a outros estímulos e perceber uma sincronia entre uma voz e seu rosto. Por estas predisposições, os bebês olham longa e freqüentemente para seus pais (pessoas que eles vêem com mais freqüência), discriminando as pessoas as quais se apegaram.

O terceiro pré-requisito cognitivo para o apego diz respeito à capacidade do bebê de construir expectativas quanto às interações recíprocas com um adulto, que lhe possibilita inclusive generalizar seqüências de interações rotineiras com seus cuidadores.

O desenvolvimento da permanência dos objetos e particularmente e em primeiro lugar da permanência da mãe, também é um pré-requisito cognitivo para o apego. Quando o conceito de objeto está estabelecido, é possível preencher as ausências físicas da mãe por meios simbólico-representacionais e por esse meio sustentar uma ligação afetiva permanente com ela, a qual significa um genuíno apego social.

O quinto pré-requisito cognitivo que possibilita o apego é a competência precoce dos bebês para a imitação, que leva a uma atenção seletiva para determinadas figuras do ambiente.

As considerações de Lamb (1981) corroboram essa articulação entre o desenvolvimento cognitivo e o afetivo. Ao descrever o desenvolvimento de expectativas nas suas interações que as crianças vão construindo ao longo do primeiro ano de vida, esse autor também consegue demonstrar a indissociabilidade dessas duas dimensões na evolução dos relacionamentos sócio-afetivos e da sua compreensão.

Dessa forma, ele propõe que antes do desenvolvimento da competência lingüística, a qual depende da capacidade de representar eventos e objetos simbolicamente, a criança desenvolve noções relativamente sofisticadas e complicadas sobre a natureza da interação social em geral e sobre as 
probabilidades de comportamento de indivíduos particulares e certas classes de pessoas. Essa compreensão se desenvolve em conseqüência da história que cada criança experimenta, o que explica a variedade entre elas com relação ao estilo social e expectativas acerca das outras pessoas.

Porém, o foco não é colocado exclusivamente sobre as expectativas com relação às outras pessoas, mas sim sobre a maneira através da qual as probabilidades de comportamento dos adultos e dos bebês se complementam umas as outras, de forma que os últimos aprendam muito sobre as características dos seus cuidadores e sobre a previsibilidade do seu comportamento. Por exemplo, o estado de angústia da criança e seu componente vocal, o choro, tem uma potência inigualável de produzir efeitos predizíveis sobre os adultos: ao ouvi-lo, eles experimentam estímulos emocionais e fisiológicos e usualmente traduzem esses estímulos numa tentativa de aliviar a angústia infantil.

Lamb (1981) considera a seqüência angústia-alívio especialmente merecedora de atenção por causa das oportunidades que ela oferece de importantes episódios de aprendizado social. O estado de angústia do bebê, com o afeto desprazeiroso que o acompanha, é seguido normalmente por uma intervenção multimodal (Ex.: segurar a criança, falar suavemente com ela, etc.). Essa seqüência promove aquisições importantes tanto para a cognição social da criança quanto para a formação dos laços de apego, pois possibilita que ela aprenda que a angústia a qual manifesta provoca uma intervenção que traz alívio, que reconheça a pessoa responsável pela transição do estado de desprazer para o prazer, que desenvolva um conceito integrado e multimodal do cuidador e que associe as características dessa pessoa com o resultado prazeiroso que ela produz.

Da mesma forma que Flavell e colaboradores (1999), Lamb (1981) também destaca a importância da compreensão da permanência das pessoas para o desenvolvimento cognitivo e sócio-emocional. Piaget (1963/1979) já destacara que a compreensão da existência das pessoas é alcançada mais rapidamente do que o reconhecimento da permanência do objeto. Para Lamb isso é o que torna possível conceber o estabelecimento de laços específicos de apego, o que está articulado ao grau de sofisticação cognitiva que tais relacionamentos vão assumindo. Além disso, um comportamento social plenamente intencional não pode ocorrer antes dessa evolução. O desenvolvimento cognitivo, portanto, permite que a criança assuma um papel diferente nas suas interações sociais e relacionamentos: uma troca para um papel de participante mais ativo e intencionalmente dirigido. Os próprios relacionamentos se tornam mais maduros em virtude da nova habilidade do bebê de constituir laços discriminados e duradouros.
Também interfere nesses laços de apego, contribuindo para as suas características, o estilo de comportamento da mãe ou do principal cuidador, quão disponíveis e apropriadas são suas respostas. É também nessa base que as crianças estarão construindo expectativas acerca do comportamento das suas figuras de apego.

Além da estrutura da interação, Lamb (1981) propõe que o conteúdo da interação também contribui para as expectativas acerca de como as pessoas irão se comportar. Assim por exemplo, o pai tem um estilo diferente do da mãe de cuidar e interagir com a criança, da mesma forma que os irmãos ou os pares. No início do seu segundo ano de vida as crianças já serão capazes de reconhecer e categorizar as pessoas usando dimensões tais como familiaridade, tamanho, gênero, sem contudo integrar todas essas informações ainda.

Todas essas aquisições contribuem para o desenvolvimento de um auto-conceito. Flavell e colaboradores (1999) acreditam que por volta dos 2 anos a criança já desenvolveu uma noção inicial de self autônomo e com poder de ação, e que este self está física e psicologicamente separado das outras pessoas, que também são autônomas e têm poder de ação. A criança também sabe que está conectada a esses objetos sociais separados de muitas maneiras. Esses conceitos emergentes de outro, selfe relações sociais podem refletir o início de consciência em relação à mente, a qual se transforma em uma teoria da mente nos anos pré-escolares, que por sua vez constitui uma base conceitual para o raciocínio da criança acerca do mundo social.

Acredita-se que o conceito de "modelos representacionais", ou "modelos funcionais" de Bowlby (1969/1990) auxilia na compreensão desse processo. Ao final do primeiro ano de vida, e durante os segundo e terceiro anos, quando adquire a linguagem, a criança se habilita a construir modelos funcionais de como esperar que o mundo físico se comporte, como a mãe e outras pessoas significativas poderão se comportar, acerca dela mesma e das interações entre todos. É a partir desse quadro de referência que a criança avalia a sua situação e traça seus planos. Tais modelos influem na percepção e na avaliação e podem ser mais ou menos válidos ou distorcidos.

Posteriormente, ao abordar os temas da separação e da perda, Bowlby (1973/1998a, 1973/1998b) retorna à discussão do conceito dos modelos representacionais, utilizando-os para a compreensão dos processos de perda e separação. No primeiro trabalho ele assinala que nos modelos representacionais do mundo que cada pessoa constrói um fator-chave é a sua visão acerca das figuras de apego, de onde podem ser encontradas e como respondem. Da mesma forma, o modelo representacional 
do self também é um elemento-chave para a noção de quão aceitável ou inaceitável ela é, aos olhos das suas figuras de apego. No segundo trabalho acrescenta que a interpretação e avaliação que fazemos de cada situação, a partir de nossos modelos representacionais, determina aquilo que sentimos. Além disso, como os dados para a construção dos modelos vêm de múltiplas fontes, há a possibilidade de existirem dados incompatíveis, podendo essa incompatibilidade, para algumas crianças, ser regular e persistente. A forma e o quanto novas informações serão integradas ao modelo existente também é uma questão discutida.

Bowlby (1988/1989) equipara o conceito de modelo representacional na teoria do apego ao de objeto interno na teoria psicanalítica das relações objetais. Ao mesmo tempo, relaciona este conceito aos processos e capacidades cognitivas, ponto que aprofundou em seu escrito sobre perdas, já citado (1973/1998b). Assim, os modelos representacionais tornam-se estabelecidos como estruturas cognitivas influentes e são baseados em experiências de vida real da criança, nas suas interações com seus pais ou cuidadores. Uma vez construídos, o autor acredita que os modelos dos pais e do self em interação tendem a persistir e passam a atuar em nível inconsciente. E que, no decorrer do desenvolvimento (na medida em que a criança seguramente apegada cresce e os pais a tratam de forma diferente), ocorre uma atualização gradual dos modelos. Por outro lado, nas crianças ansiosamente apegadas parece haver uma dificuldade e rigidez maior na atualização dos modelos.

Acredita-se que o conceito de modelos representacionais internos estabelece uma intersecção importante entre os conteúdos da teoria do apego e da teoria da cognição social.

Da mesma forma que a cognição social envolve a compreensão sobre as pessoas, suas ações e a relação entre os próprios sentimentos, pensamentos e ações, tanto quanto a relação entre esses aspectos pessoais e os aspectos correspondentes nas outras pessoas, os modelos representacionais internos formulados por Bowlby têm uma abrangência semelhante. Bee (1996) destaca que esses modelos "contêm expectativas de seqüências de comportamento, regras para o comportamento com vários indivíduos e a interpretação das ações dos outros" (p. 323).

Assim, uma vez estabelecidos, esses modelos conformam e explicam as experiências, além de afetar a memória e a atenção. $\mathrm{O}$ modelo afeta ainda nosso comportamento, implicando na tendência a recriarmos, em cada novo relacionamento, o padrão com o qual estamos familiarizados: é mais fácil e provável perceber e lembrar as experiências que se ajustam ao nosso modelo e não perceber ou esquecer as experiências que não se ajustam. Tal concepção é compartilhada por West e Sheldon-Keller (1994).

A contribuição de Baldwin e colaboradores (1996) reforça essa possibilidade de articulação entre a teoria da cognição social e o conceito de modelos representacionais. Esses autores propõem uma conceitualização dos modelos representacionais de apego da perspectiva da teoria da cognição social, sugerindo que as pessoas possuem "esquemas relacionais" que correspondem a determinadas orientações de apego, e que a relativa disponibilidade e acessibilidade desse conhecimento delineia seus pensamentos sobre os relacionamentos. E acreditam que essa articulação tem um potencial heurístico considerável, na medida em que as estruturas cognitivas vinculadas ao apego podem possibilitar e facilitar uma maior atenção e conscientização das pessoas nas suas relações, reconhecendo e discriminando os seus padrões dessas interações.

Baldwin e colaboradores (1996) e Cook (2000) questionam a fixidez com a qual os modelos representacionais relativos às primeiras figuras de apego moldariam os relacionamentos posteriores. Baseiam-se em pesquisas que realizaram explorando o apego adulto e acreditam que a segurança do apego adulto diz respeito a relacionamentos específicos. Sublinham a influência e importância da cognição para essa variabilidade e flexibilidade em relação aos modelos anteriores da infância. Assim, o estilo de apego elaborado na infância com os cuidadores primários não seria generalizável para todos os demais relacionamentos. Haveria variações na segurança do apego que dependem de cada relacionamento em particular, das características do parceiro, das experiências que se sucedem, da reciprocidade presente ou não em cada relação. Baldwin e colaboradores, através da sua abordagem que articula as contribuições da teoria da cognição social e aquelas do campo da teoria do apego, estão convencidos de que a forma através da qual a informação é processada, em cada experiência de relacionamento significativa, gera representações específicas e outras mais abstratas e gerais, que se combinam numa estrutura associativa. Tal processo é dinâmico e permanentemente atualizado, o que contribuiria para a plasticidade dos modelos representacionais. E mais recentemente, Cook enfatiza a natureza interpessoal da segurança do apego, em oposição à intrapsíquica, focalizando sua atenção na forma segundo a qual os processos sociais contribuem para manter ou modificar os modelos representacionais internos de relacionamento. E conclui que tais modelos podem não ser tão "internos" assim, o que nos conduz a considerar também o papel das narrativas sócio-culturais enquanto limites das representações possíveis. 
Portanto, além das experiências, as mudanças cognitivas têm um impacto sobre a natureza e a organização das concepções dos relacionamentos. $\mathrm{Na}$ adolescência, o pensamento e o raciocínio se tornam crescentemente abstratos, multi-dimensionais e auto-reflexivos. Várias representações mentais complexas podem ser comparadas simultaneamente. Essa capacidade crescente de processar informações possibilita ao adolescente contemplar seu mundo interno de pensamentos e sentimentos, e comparálo com o dos outros, o que lhe oferece novas ferramentas cognitivas para o processamento da informação relacional (ou seja, da cognição social) e para construir significados acerca das suas experiências de relacionamento. Torna-se mais provável a reavaliação e atualização das suas concepções de relacionamento, pois os avanços na capacidade de tomada de perspectiva e de auto-reflexão possibilitam ao adolescente contrastar concepções existentes com alternativas potenciais e a conceber as suas concepções como potencialmente transformáveis, mais do que como construções estáticas. Enquanto na infância as concepções dos relacionamentos se modificam principalmente sob o influxo de mudanças concretas nas relações, na adolescência as mudanças ocorrem a partir do insight e da reflexão.

\section{Cognição e Afeto: Duas Dimensões Indissociáveis}

A partir dessa discussão, pode-se concluir que a separação entre afeto e cognição é uma ficção e ela acontece no plano teórico muito mais por conveniência analítica do que por se tratar da abordagem de faculdades distintas e independentes da mente. Esta convicção é apoiada pelas teorizações de vários autores (Fiske \& Taylor, 1991; Flavell \& cols., 1999; Forgas, 2001).

Nos últimos 20 anos, entretanto, esse panorama vem se alterando, podendo se observar no campo da cognição social a emergência de estudos voltados para a compreensão do afeto e sua interação com a cognição. Algumas contribuições descrevem como as cognições influenciam as emoções, outras focalizam como o afeto influencia as cognições e algumas ainda partem da premissa de que afeto e cognição são separados e independentes, conforme citam Fiske e Taylor (1991).

Forgas (2001) afirmou que "o afeto não é uma parte incidental, mas sim é parte inseparável de como nós vemos e representamos o mundo em volta de nós" (p. 11). Concordamos com esse autor e também com Cicchetti e Pogge-Hesse (1981) quando alertaram que para o estudo das emoções é importante que os teóricos do desenvolvimento assumam algumas posições, com relação a determinar o papel da criança na construção da realidade, no sentido de considerá-la como um construtor ativo ou receptor passivo do ambiente e considerar como a criança representa a informação que capta nele. Também é necessário especificar o papel que é atribuído ao ambiente no processo de desenvolvimento. E, sobretudo, é importante levar em conta que o relacionamento entre cognição e emoção é crucial para a compreensão do desenvolvimento em geral. Além disso, a forma como este relacionamento é visto influencia diretamente como o desenvolvimento emocional é conceitualizado. A emoção e a cognição deveriam ser estudadas concorrentemente. Por exemplo, a distinção entre self e outro é um pré-requisito para a capacidade do bebê de investir emocionalmente no mundo externo e por outro lado ele aprende muito sobre ele mesmo e o mundo na medida em que interpreta os seus estados emocionais. Como cada sistema (afeto e cognição) provoca ou não mudanças no outro é uma questão subjacente.

Por essas razões, Cicchetti e Pogge-Hesse (1981) destacam que os pesquisadores deveriam se movimentar de um nível microscópico de análise para um nível mais integrativo, que possibilitasse a formulação de uma teoria mais compreensiva da relação entre o desenvolvimento emocional e o cognitivo. As teorias que têm sido formuladas são complementares em vários aspectos, os quais podem ser frutíferos como guias para novas investigações.

Westen (1991) discutiu as possibilidades de integração entre os métodos e conceitos da cognição social e da teoria psicanalítica das relações objetais, uma vez que focalizam os processos afetivos e cognitivos mediadores do funcionamento interpessoal. Embora cada um desses enquadres teóricos aborde o estudo dos processos cognitivos e sócio-afetivos a partir de diferentes filosofias de ciência, diferentes bases de dados e diferentes metáforas da mente, essa autora acredita que ambos poderiam se beneficiar com as contribuições um do outro. A pesquisa no campo da cognição social poderia se beneficiar da compreensão psicanalítica acerca dos processos afetivos, defensivos, e das representações inconscientes. As abordagens das relações objetais poderiam se beneficiar das metodologias de estudo da cognição social, e dos seus achados a respeito do desenvolvimento.

Acredita-se que a articulação de conceitos da teoria da cognição social e das teorias que abordam os processos de formação dos vínculos afetivos pode criar um campo conceitual novo, o qual demanda uma teorização aprofundada. A complexidade dessa interface e articulação está longe de ser esgotada e convida os teóricos a debruçarem-se sobre ela.

As demandas atuais no campo da construção do conhecimento científico apontam cada vez mais para a necessidade de se pensar a partir de uma perspectiva transdisciplinar. 
Pensamos também que a articulação de conceitos das teorias aqui discutidas poderá ter uma implicação importante no âmbito da clínica psicológica, na medida em que nos permite vislumbrar novas possibilidades e propostas de intervenção, alicerçadas no conhecimento que daí poderia emergir.

\section{Referências}

Baldwin, M. W., Keelan, J. P. R., Fehr, B., Enns, V. \& Koh-Rangarajoo, E. (1996). Social-cognitive conceptualization of attachment working models: Availability and accessibility effects. Journal of Personality and Social Psychology, 71, 94-109.

Bee, H. (1996). A criança em desenvolvimento ( $7^{\mathrm{a}}$ ed.). Porto Alegre: Artes Médicas.

Bowlby, J. (1990). Apego e perda: Apego, a natureza do vínculo (Vol 1, $2^{\mathrm{a}}$ ed.). São Paulo: Martins Fontes. (Original publicado em 1969)

Bowlby, J. (1998a). Apego e perda: Separação, angústia e raiva (Vol. 2, 3ª ed). São Paulo: Martins Fontes. (Original publicado em 1973)

Bowlby, J. (1998b). Apego e perda: Perda, tristeza e depressão (Vol. 3, $2^{\mathrm{a}}$ ed). São Paulo: Martins Fontes. (Original publicado em 1973)

Bowlby, J. (1997). Formação e rompimento dos laços afetivos ( $3^{\mathrm{a}} \mathrm{ed}$.). São Paulo: Martins Fontes. (Original publicado em 1979)

Bowlby, J. (1989). Uma base segura: A plicaçoes clinicas da teoria do apego. Porto Alegre: Artes Médicas. (Original publicado em 1988)

Cicchetti, D. \& Pogge-Hesse, P. (1981). The relation between emotion and cognition in infant development. Em M. Lamb \& L. Sherrod (Orgs.), Infant social cognition: Empirical and theoretical considerations (pp. 205-272). Hillsdale, New Jersey: Lawerence Erlbaum.

Cook, W. L. (2000). Understanding attachment security in family context. Journal of Personality and Social Psychology, 78, 285-294.

Fiske, S. T. \& Taylor, S. E. (1991). Social cognition (2 ed). Nova York: McGrawHill.

Flavell, J. H., Miller, P. H. \& Miller, S. A. (1999). Desenvolvimento cognitivo (3ª ed.). Porto Alegre: Artes Médicas. (Original publicado em 1993)

Forgas, J. P. (2001). Feeling and thinking: The role of affect in social cognition. United Kingdom: Cambridge University Press.
Frye, D. (1981). Developmental changes in strategies of social interaction. Em M. Lamb \& L. R. Sherrod (Orgs.), Infant social cognition: Empirical and theoretical considerations (pp. 315-331). Hillsdale, New Jersey: Lawerence Erlbaum.

Fu, V. R., Goodwin, M. P., Sporakowki, M. J. \& Hinkle, D. E. (1987). Children's thinking about familiy characteristcs and parent attributes. Journal of Genetic Psychology, 148, 153-166.

Lamb, M. E. (1981). The developmental of social expectations in the first year of life. Em M. E. Lamb \& Sherrod, L. R. (1981). Infant social cognition: Empirical and theoretical considerations (pp. 155-175). Hillsdale, New Jersey: Lawerence Erlbaum.

Lamb, M. E. \& Sherrod, L. R. (1981). Infant social cognition: Empirical and theoretical considerations. Hillsdale, New Jersey: Lawerence Erlbaum.

Olson, G. M. (1981). The recognition of specific persons. Em M. E. Lamb \& L. R. Sherrod (Orgs.), Infant social cognition: Empirical and theoretical considerations (pp. 37-59). Hillsdale, New Jersey: Lawerence Erlbaum.

Oster, H. (1981). "Recognition" of emotional expression in infancy? Em M. R. Lamb \& L. R. Sherrod (Orgs.), Infant social cognition: Empirical and theoretical considerations (pp. 85-125). Hillsdale, New Jersey: Lawrence Erlbaum.

Piaget, J. (1979). A construção do real na criança ( $3^{\mathrm{a}}$ ed.). Rio de Janeiro: Zahar. (Original publicado em 1963)

Ramires, V. R. R. (2002). O amor e suas vicissitudes: As concepp̧ões de crianças e adolescentes. Tese de Doutorado não-publicada, Programa de Estudos PósGraduados em Psicologia Clínica, Pontifícia Universidade Católica de São Paulo. São Paulo, SP.

Rothbard, J. C. \& Shaver, P. R. (1994). Continuity of attachment across the life span. Em M. B. Sperling \& W. H. Berman (Orgs.), Attachment in adults: Clinical and developmental perspectives (pp. 31-71). New York: The Guilford Press.

West, M. L. \& Sheldon-Keller, A. E. (1994). Patterns of relating: An adult attachment perspective. New York: The Guilford Press.

Westen, D. (1991). Social cognition and object relations. Psychological Bulletin, 109, 429-455.

Sobre a autora

Vera Regina Röhnelt Ramires é Psicóloga, Doutora em Psicologia Clínica pela Pontifícia Universidade Católica de São Paulo. É Professora da Universidade do Vale do Rio dos Sinos (UNISINOS). 